\title{
Interrelation of inflammation and oxidative stress in liver cirrhosis
}

\author{
MIHNEA MARIAN POMACU ${ }^{1,2^{*}}$, MARIA DIANA TRAȘCA ${ }^{2 *}$, VLAD PĂDUREANU $^{3}$, \\ ANA MARIA BUGĂ ${ }^{1}$, ANA MARINA ANDREI ${ }^{1}$, ELENA CAMELIA STĂNCIULESCU ${ }^{1}$, \\ ILEANA MONICA BANIȚĂ ${ }^{4}$, DUMITRU RĂDULESCU ${ }^{5}$ and CĂTĂLINA GABRIELA PISOSCHI ${ }^{1}$
}

\author{
${ }^{1}$ Department of Biochemistry, University of Medicine and Pharmacy of Craiova; ${ }^{2} 4$ th Department-Medical Specialties, \\ First Clinic of Internal Medicine, Clinical City Hospital 'Filantropia', University of Medicine and Pharmacy of Craiova; \\ ${ }^{3}$ Department of Internal Medicine, County Hospital of Craiova, University of Medicine and Pharmacy of Craiova; \\ ${ }^{4}$ Department of Histology, ${ }^{5}$ Department of General Surgery, University of \\ Medicine and Pharmacy of Craiova, 200349 Craiova, Romania
}

Received January 22, 2021; Accepted February 22, 2021

DOI: $10.3892 / \mathrm{etm} .2021 .10034$

\begin{abstract}
Recently, the trend of research has been focused on the role of hematological indicators in assessing the activities of various diseases. The aim of the present study was to determine the usefulness of such hematological indicators for assessment of the relationship between inflammation and oxidative stress in order to provide new predictive tools for a non-invasive investigation of disease outcome for liver cirrhosis patients. A total of 35 subjects with compensated or decompensated liver cirrhosis and 10 age-matched healthy volunteers were included in this study. The patients were divided into two groups: Group 1, patients with toxic metabolic cirrhosis due to ethanol consumption; group 2, patients with liver cirrhosis following hepatitis B virus (HBV) and hepatitis $\mathrm{C}$ virus (HCV) infection. Using hematological data obtained after the complete counting of peripheral blood cells, the monocyte/lymphocyte (MLR), neutrophil/lymphocyte (NLR) and platelet/lymphocyte (PLR) ratios as well as systemic immune inflammation biomarkers were determined. The erythrocyte sedimentation ratio (ESR), C-reactive protein (CRP), fibrinogen and biochemical parameters related to liver function were also registered. Thiobarbituric acid reactive substances (TBARS), protein carbonyl content (PCARB),
\end{abstract}

Correspondence to: Dr Ana Maria Bugă, Department of Biochemistry, University of Medicine and Pharmacy of Craiova, 2-4 Petru Rareș Street, 200349 Craiova, Romania

E-mail: ana.buga@umfcv.ro

Dr Vlad Pădureanu, Department of Internal Medicine, County Hospital of Craiova, University of Medicine and Pharmacy of Craiova, 2-4 Petru Rareș Street, 200349 Craiova, Romania

E-mail: vldpadureanu@yahoo.com

*Contributed equally

Key words: liver cirrhosis, oxidative stress, inflammation, neutrophil/ lymphocyte ratio, monocyte/lymphocyte ratio, platelet/lymphocyte ratio and total antioxidant capacity (TAC) were also investigated in the peripheral blood samples of healthy subjects and liver cirrhosis patients. The results revealed that NLR, MLR and PLR were significantly increased in group 2 . PLR was significantly increased in group 1 compared with that noted in the control group. TBARS and PCARB were increased in patients from group 1 compared to patients from group 2 and the control group. However, no difference in TAC was found between the liver cirrhosis groups and the control. We showed that the pro-inflammatory status of liver cirrhosis patients can be easily appreciated by NLR, MLR but not PLR. However, the increase in these ratios was not significantly associated with a decrease in the antioxidant capacity and an augmentation of oxidative stress markers for the patients diagnosed with cirrhosis included in the two groups of study.

\section{Introduction}

Oxidative stress, defined as the imbalance between pro-oxidants and antioxidant capacity, plays an important role in the course of inflammatory, metabolic and proliferative chronic liver disease (CLD). Chronic liver injury can be manifested as fibrosis, cholestasis, necrosis and cirrhosis (1). Liver cirrhosis is the final stage of various types of CLD and fibrosis is the precursor of cirrhosis. The burden of liver disease is underestimated but continues to grow worldwide (2). Ethanol consumption and chronic infections due to hepatitis B virus (HBV) and/or hepatitis $\mathrm{C}$ virus (HCV) constitute the main causes of liver cirrhosis which was reported to represent the 11th most common cause of mortality worldwide in 2018 (3), with first-year mortality ranging from 1 to 57\% depending on the stage $(1,4)$.

Many types of cells, cytokines and microRNAs are involved in the initiation and progression of liver fibrosis and cirrhosis. Pathological features are common to all cases of liver cirrhosis, including hepatocyte degeneration and necrosis, replacement of liver parenchyma by fibrotic tissues and regenerative nodules, and loss of liver function. The liver that is exposed to high amounts of ethanol undergoes structural and functional alterations as a consequence of two linked 
phenomena: Oxidative stress and inflammation (5). Ethanol may increase the production of reactive oxygen and nitrogen species (ROS, RNS), and these reactive intermediates are able to induce pro-fibrogenic cytokines and the release of several inflammatory markers and collagen synthesis during the progression of liver fibrosis $(1,6)$. ROS are oxygen-containing molecules that are produced during normal metabolism. The organism has two types of systems able to neutralize the harmful effects of endogenous ROS, enzymatic and non-enzymatic antioxidants (7). Under normal circumstances, the liver maintains a balance between internal antioxidants and ROS in order to be able to neutralize the free radicals generated by viruses and various endogenous and exogenous compounds processed by the liver. Under certain conditions, the oxidative to antioxidative balance shifts towards the oxidative status as a result of an increase in ROS production or antioxidant depletion. However, when the liver is overwhelmed by continuous oxidative insults (e.g., long-lasting ethanol abuse, infection with $\mathrm{HBV}$ or $\mathrm{HCV}$ ), the damage from free radicals increases, resulting in inflammation and fibrosis (8).

Oxidative stress causes liver injury by the alteration of main biological molecules (DNA, proteins, and lipids) (9). We know from previous studies that DNA and protein oxidation as well as lipid peroxidation products are involved in the modulation of signaling pathways associated with gene transcription, protein expression, apoptosis, and hepatic stellate cell activation, contributing to both the onset and progression of liver fibrosis $(10,11)$. Regarding inflammation, it is an essential event in the immune response manifested as infiltration of inflammatory cells to fight against various aggressive stimuli.

The close interplay between oxidative stress and inflammation in the development of liver disease has stimulated the interest of researchers for a long time. Excessive inflammatory cells may produce more ROS and RNS and further these are able to increase the expression of genes coding proinflammatory cytokines. The general consensus is that oxidative stress and inflammation are tightly correlated and create a vicious cycle which is involved in the progression to cirrhosis and ultimately hepatocellular carcinoma of liver diseases (12).

Recently, the trend of research has been focused on the role of hematological markers of inflammation from complete blood count (CBC) panel [ratios including neutrophil/lymphocyte (NLR), monocyte/lymphocyte (MLR) and platelet/lymphocyte (PLR)] in assessing the prognosis of various disorders (13-17). Thus, NLR and PLR have been validated as prognostic markers in cancer, sepsis, cardiac conditions, pneumonia and acute respiratory distress syndrome (18-20). Few studies have evaluated the role of these ratios as prognostic indexes of disease outcome in patients with liver cirrhosis. According to our knowledge, none of these reported the use of these indexes to assess the association between oxidative stress, inflammation and the severity of liver disease.

Therefore, the aim of the present study was to determine the usefulness of such hematological indicators to assess the relationship between inflammation and oxidative stress in order to provide new predictive tools for a non-invasive paraclinical investigation of disease outcome in liver cirrhosis patients.

\section{Patients and methods}

Statement of ethics. According to the European Union Guidelines (Declaration of Helsinki), the study received the approval of the Institutional Ethics Committee of the University of Medicine and Pharmacy of Craiova (registration no. 116/11.11.2019) and the registered participants gave their written informed consent to be included.

Patients. A total of 35 subjects, hospitalized at the First Clinic of Internal Medicine, Clinical City Hospital 'Filantropia' and Second Clinic of Internal Medicine, County Hospital of Craiova, Romania from November 2019 to February 2020, with compensated or decompensated liver cirrhosis aged between 38-75 years and 10 age-matched healthy volunteers were enrolled in this study. The diagnosis was established based on medical history, clinical examination, laboratory tests, ultrasonography and endoscopy. Decompensated liver cirrhosis is associated with ascites, esophageal varices or hepatic encephalopathy. Exclusion criteria were the following: Pregnancy, drug abuse, comorbidities that could increase the systemic inflammation (e.g., diabetes, metabolic syndrome, inflammatory and autoimmune diseases), corticoids or non-steroidal anti-inflammatory drug use (17). The patients were divided into two groups: Group 1, patients $(n=25)$ with toxic metabolic cirrhosis due to ethanol consumption (all of these patients had consumed at least $70 \mathrm{~g}$ of pure alcohol per day for more than 5 years); group 2, patients $(n=10)$ with liver cirrhosis following $\mathrm{HBV}$ and $\mathrm{HCV}$ infection. The control group, included 10 age-matched healthy subjects without any clinical or paraclinical sign of disease.

Sample collection and handling. In the morning, after a minimum of $12 \mathrm{~h}$ of fasting, blood samples were collected in commercially available covered test tubes without any anticoagulant and, in order to prevent blood clotting, in lavender topped $\mathrm{K}_{2}$ EDTA BD vacutainers (Becton-Dickinson). Blood samples collected in $\mathrm{K}_{2}$ EDTA tubes were used to perform a complete blood count (CBC).

For each patient, a sample of blood was also collected in black capped BD ESR (Becton-Dickinson) tubes. Plasma and blood cell fractions were separated by centrifugation of blood also collected in vacutainers containing $\mathrm{K}_{2}$ EDTA at $2,000 \mathrm{x} \mathrm{g}$, for $10 \mathrm{~min}$, at $4^{\circ} \mathrm{C}$ (5417R Eppendorf centrifuge; Eppendorf AG). Immediately after separation, the plasma was aliquoted in Eppendorf tubes and stored under proper conditions (at $-80^{\circ} \mathrm{C}$, avoiding repeated freezing/refreezing cycles) until determination of several oxidative stress markers. The sediment was processed to obtain a hemolysate that was preserved for further analyses.

Serum was separated by centrifugation of blood collected in red topped BD vacutainers (Becton-Dickinson) at $1,000 \mathrm{x} \mathrm{g}$ for $10 \mathrm{~min}$, after which it was allowed to clot for $20 \mathrm{~min}$ at room temperature, and used for the measurement of several inflammatory markers and biochemical parameters.

Laboratory and clinical assessments. We recorded the following general information for each subject: Age, sex, time of disease progression. Counts of white blood cells (WBC), red blood cells (RBC), neutrophils, monocytes, lymphocytes 
and platelets were performed in samples of peripheral blood obtained by standard venipuncture in $\mathrm{K}_{2}$ EDTA BD vacutainers using an automatic flow cytometry analyzer (CELL-DYN Ruby System; Abbott Diagnostics). Using the hematological data, we calculated the monocyte/lymphocyte ratio (MLR), neutrophil/lymphocyte ratio (NLR) and platelet/lymphocyte ratio (PLR) by dividing the number of respective subtypes of blood cells (monocytes, neutrophils and platelets) by lymphocyte number (21) and also a systemic immune-inflammation index (SII) according to the formula: SII=platelet count $\mathrm{x}$ neutrophil count/lymphocyte count (22). The erythrocyte sedimentation ratio (ESR) was assessed according to the Westergren method. C-reactive protein (CRP) analysis was performed using an automated immunoassay analyzer (Cobase411; Roche Diagnostics $\mathrm{GmbH}$ ). Fibrinogen was measured using an ACL Top 500 coagulometer (Instrumentation Laboratory, USA). Total proteins, albumin, alanine-aminotransferase (ALT), aspartate aminotransferase (AST), alkaline phosphatase (Palk) and $\gamma$-glutamyl transpeptidase (GGT) were assessed using an automated analyzer Architect c8000 (Abbott Diagnostics).

Lipid peroxidation analysis as thiobarbituric acid reactive substances assay. The thiobarbituric acid reactive substances (TBARS) assay in plasma was performed using a spectrophotometric method in order to evaluate the lipid peroxidation level as previously described $(23,24)$. The lipid peroxidation level was evaluated by quantifying malondialdehyde (MDA) concentration, a major product of fatty acid peroxidation, from deproteinized plasma. Human plasma $(0.1 \mathrm{ml})$ was treated with $5 \%$ trichloroacetic acid (TCA) and $0.2 \mathrm{M}$ Tris- $\mathrm{HCl}$ $\mathrm{pH}=4.7(\mathrm{v} / \mathrm{v})$. After $10 \mathrm{~min}$ of incubation at room temperature, the sample was mixed with $1 \mathrm{ml}$ of $0.55 \mathrm{M}$ thiobarbituric acid (TBA) in $2 \mathrm{M}$ sodium sulphate, heated at $90^{\circ} \mathrm{C}$ for $45 \mathrm{~min}$ and cooled in ice (25). After cooling, the mixture was centrifuged at $15,000 \mathrm{x} \mathrm{g}$ for $3 \mathrm{~min}$ in a refrigerated centrifuge (Eppendorf 5417R; Eppendorf AG). MDA reacts with TBA and forms a pink color product which has a specific absorption at $532 \mathrm{~nm}$. The optical density (OD) was measured using an UV-VIS spectrophotometer (Kruss). The TBARS concentration was calculated using the molar extinction coefficient of MDA $\left(1.55 \times 10^{5} \mathrm{M}^{-1} \mathrm{~cm}^{-1}\right)$. The results are expressed as $\mu \mathrm{mol} / 1 \mathrm{TBARS}$. Except TBA produced by Fluka, all other reagents used were provided by Sigma-Aldrich; Merck KGaA.

Protein carbonyl content assay. A spectrophotometric assay using 2,4-dinitrophenylhydrazine (DNPH) was performed to assess carbonylated protein (PCARB) content as a marker of protein oxidation $(23,25,26)$. The plasma samples were mixed with $20 \%$ TCA (v/v), incubated for $15 \mathrm{~min}$ on ice and separated by centrifugation at $15,000 \mathrm{x} \mathrm{g}$, for $5 \mathrm{~min}$ at $4^{\circ} \mathrm{C}$. After centrifugation, the supernatant was discarded and the pellet was treated with $0.5 \mathrm{ml} 10 \mathrm{mM} \mathrm{DNPH}$ in $2.5 \mathrm{M} \mathrm{HCl}$. The samples were incubated in the dark for $1 \mathrm{~h}$ with intermittent shaking every $15 \mathrm{~min}$. After incubation, the upper phase was removed and two washing steps were performed with ethanol:ethyl acetate $(1: 1, \mathrm{v} / \mathrm{v})$ to remove the excess DNPH. The protein pellet was solved in $1 \mathrm{ml}$ of $5 \mathrm{M}$ urea $(\mathrm{pH}=2.3)$ at $37^{\circ} \mathrm{C}$ for $10 \mathrm{~min}$ and separated by centrifugation at $15,000 \mathrm{x} \mathrm{g}$, for $5 \mathrm{~min}$ at $4^{\circ} \mathrm{C}$. Finally, the OD of the samples was measured at $375 \mathrm{~nm}$ using a UV-VIS spectrophotometer
Table I. Demographic and biochemical findings of the patients in the liver cirrhosis subgroups.

\begin{tabular}{lcc}
\hline Characteristic & $\begin{array}{c}\text { Group 1 } \\
\text { (alcoholic } \\
\text { cirrhosis) }\end{array}$ & $\begin{array}{c}\text { Group 2 } \\
\text { (cirrhosis due to } \\
\text { viral infection) }\end{array}$ \\
\hline Mean age (years) & $63.17 \pm 10.4$ & $59.14 \pm 10.52$ \\
Sex ratio (M/F) & $19: 6$ & $7: 3$ \\
ALT (UI) & $31.63 \pm 20.96$ & $31.28 \pm 10.07$ \\
AST (UI) & $62.04 \pm 58.75$ & $49.85 \pm 24.43$ \\
GGT (UI) & $134.58 \pm 143.16$ & $77.83 \pm 74.69$ \\
Palk (UI) & $226.52 \pm 184.26$ & $291.66 \pm 149.52$ \\
Total protein (g/dl) & $7.35 \pm 0.83$ & $7 \pm 0.28$ \\
Albumin $(\mathrm{g} / \mathrm{dl})$ & $3.35 \pm 0.89$ & $2.92 \pm 0.66$ \\
Fibrinogen $(\mathrm{mg} / \mathrm{dl})$ & $246.66 \pm 76.78$ & $406.25 \pm 17.42$
\end{tabular}

Data are expressed as the mean $\pm \mathrm{SD}$. ALT, alanine transaminase; AST, aspartate transaminase; GGT, $\gamma$-glutamyl transpeptidase; Palk, alkaline phosphatase.

(Kruss). The PCARB content was calculated based on the molar extinction factor of DNFH $\left(22,000 \mathrm{M}^{-1} \mathrm{~cm}^{-1}\right)$. PCARB concentration is expressed as $\mathrm{nmol} / \mathrm{mg}$ of protein. Total protein concentration in the samples was assessed using Bradford method (27). All reagents used were provided by Sigma-Aldrich; Merck KGaA.

Total antioxidant capacity (TAC) assay. TAC assay is one of the analyses usually performed to assess the antioxidant status in human blood samples related to various diseases. Evaluation of TAC characterizes the general ability of the body to fight oxidative stress by making antioxidant compounds. TAC can be easily assessed in human plasma using a spectrophotometric method $(24,28)$. Plasma samples diluted at 1:25 in phosphate-buffered saline (PBS, $\mathrm{pH}=7.4$ ) were mixed with $0.1 \mathrm{mM} 2,2$ diphenyl-1-picrylhydrazyl radical reagent $(\mathrm{DPPH}, \mathrm{v} / \mathrm{v})$ and incubated in a dark room for $30 \mathrm{~min}$. After incubation, the samples were separated by centrifugation for $3 \mathrm{~min}$ at 20,000 x g and OD was read at $520 \mathrm{~nm}$ using a UV-VIS spectrophotometer. TAC was expressed as mmol DPPH/l. All reagents used were provided by Sigma-Aldrich; Merck KGaA.

Statistical analysis. Data were analyzed using GraphPad Prism 5.0 software (GraphPad Software, Inc.). Data are expressed as mean \pm standard deviation (SD). The comparison of oxidative stress markers between groups was performed using several statistical tests: Unpaired non-parametric Mann-Whitney t-test, one-way ANOVA with Tukey's and Bonferroni's multiple comparison tests. A P-value $<0.05$ was considered to indicate a statistically significant difference.

\section{Results}

Demographic data, biochemical and hematological markers of inflammation. We included in this study 35 patients with liver cirrhosis divided into two groups according to the etiological 
Table II. Hematological markers of inflammation in the subjects from the liver cirrhosis subgroups and healthy control group.

\begin{tabular}{lccc}
\hline Characteristic & $\begin{array}{c}\text { Group 1 } \\
\text { (alcoholic } \\
\text { cirrhosis) }\end{array}$ & $\begin{array}{c}\text { Group 2 } \\
\text { (cirrhosis due to } \\
\text { viral infection) }\end{array}$ & Control group \\
\hline Mean age (years) & $63.17 \pm 10.4$ & $59.14 \pm 10.52$ & $56.4 \pm 6.73$ \\
Sex ratio (M/F) & $19: 6$ & $7: 3$ & $7: 3$ \\
ESR (mm/h) & $55(12-120)$ & $43.42(18-90)$ & $8.4(7-8)$ \\
CRP & Negative $(\mathrm{n}=22)$ & Negative $(\mathrm{n}=9)$ & Negative \\
& Positive $(\mathrm{n}=3)$ & Positive $(\mathrm{n}=1)$ & \\
\hline
\end{tabular}

ESR, erythrocyte sedimentation ratio; CRP, C-reactive protein.

factor: Group 1, patients with toxic metabolic cirrhosis due to ethanol consumption and group 2, patients with liver cirrhosis following $\mathrm{HBV}$ and $\mathrm{HCV}$ infection.

Demographic data and various biochemical findings for the patients in the liver cirrhosis subgroups are presented in Table I.

Table II contains a parallel between the hematological markers of inflammation found in the patients from the healthy control group and the liver cirrhosis subgroups.

We showed that NLR was significantly increased in group 2 compared with group $1(\mathrm{P}<0.01)$ and with the control group $(\mathrm{P}<0.001)$ (Fig. 1).

Receiver operator characteristic (ROC) analysis, area under the curve (AUC) and 95\% confidence interval (CI) were performed in order to establish hematological markers of inflammation performance.

ROC analysis of NLR was performed for group 1 and group 2 vs. the control group. We found AUC of 0.79 (95\% CI: 0.64-0.94) for NLR in group 1 vs. the control group and AUC of 1.00 (95\% CI: 1.00-1.00) for NLR in group 2 compared with the control group (Fig. 2).

As a biomarker of the immune system, we found that the MLR was significantly increased in group 2 compared with that in the control group $(\mathrm{P}<0.01)$ (Fig. 3). The ratio was also increased in patients from group 1 compared with the control, yet this difference was not significant.

ROC analysis of MLR was performed for group 1 and group 2 vs. the control group. We found an AUC of 0.9136 (95\% CI: 0.82-1) for MLR in group 1 vs. the control group and AUC of 0.97 (95\% CI: 0.9-1.04) for MLR in group 2 compared with the control group (Fig. 4).

In addition, we showed that the PLR was significantly increased in group 2 compared with group $1(\mathrm{P}<0.01)$ and in the group 1 compared to control group $(\mathrm{P}<0.05)$ (Fig. 5).

ROC analysis of PLR was performed for group 1 and 2 vs. the control group. We found AUC of 0.79 (95\% CI: 0.64-0.95) for PLR in group 1 vs. the control group and AUC of 0.62 (95\% CI: 0.35-0.9) for PLR in group 2 compared with the control group (Fig. 6).

Variation in the ratios for various blood cells between the subgroups with liver cirrhosis was sustained by the difference between the SII values $\left(505.55 \times 10^{9} \pm 106.16 \times 10^{9}\right.$ cells $/ 1$ for the patients with viral cirrhosis from group 2 , compared to $410.56 \times 10^{9} \pm 280.91 \times 10^{9}$ cells $/ 1$ for those from group 1 , with alcoholic liver disease).

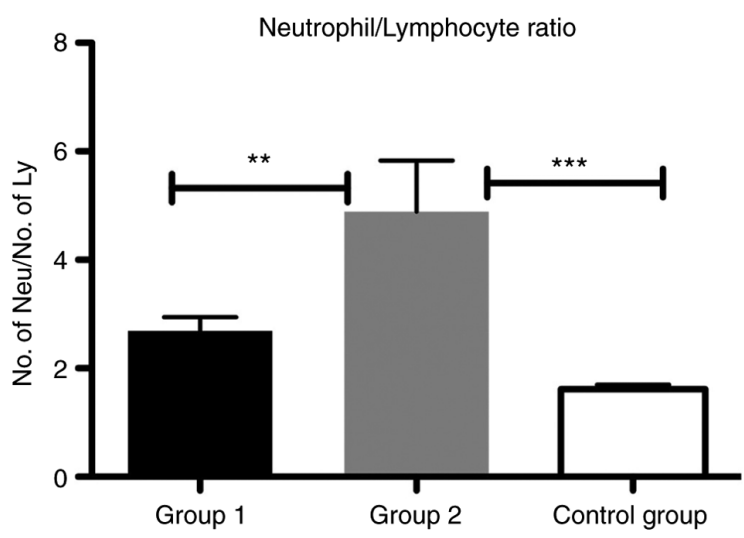

Figure 1. Bar plot (mean \pm SEM) of NLR in the liver cirrhosis patients from group 1 and 2 compared with the control group. One-way ANOVA test, ${ }^{* *} \mathrm{P}<0.01,{ }^{* * *} \mathrm{P}<0.001$. NLR, neutrophil/lymphocyte ratio.

Markers of oxidative stress and total antioxidant capacity. The effects of ROS damage against biomolecules, such as quantification of plasma TBARS for lipid peroxidation and plasma PCARB for protein oxidation, were assessed in the controls and patients from the liver cirrhosis subgroups. We found a significantly increased level of TBARS in group 1 compared with group $2(\mathrm{P}<0.05)$ and also for group 1 compared with the control group $(\mathrm{P}<0.01)$ (Fig. 7).

In our study, the level of protein damage by carbonylation of the lateral chain of amino acids from protein structure (PCARB) was significantly increased in group 1 compared with group 2 in the patients with liver cirrhosis $(\mathrm{P}<0.05)$ (Fig. 8).

Regarding the total antioxidant defense capacity (TAC), we found that the values did not differ significantly between the control age-matched group and patients from the two groups with liver cirrhosis (Fig. 9).

Unfortunately, oxidative stress markers (TBARS and PCARB) did not correlate significantly with any of the ratios between blood cells investigated as predictive markers for the unfavorable progression of liver cirrhosis.

\section{Discussion}

To the best of our knowledge, this is the first study that aimed to evaluate the association of hematological markers of inflammation and oxidative stress in liver cirrhosis patients. In the present study, we found that the patients included showed 

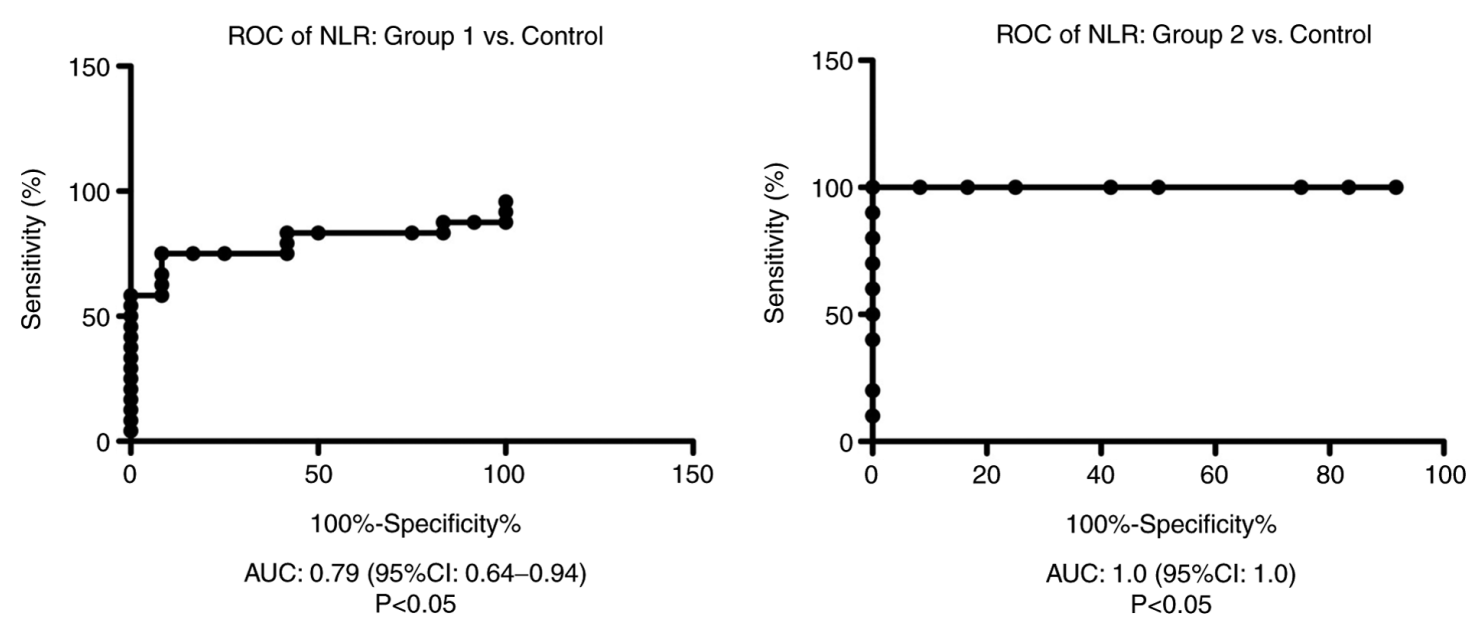

Figure 2. ROC diagram of NLR in the liver cirrhosis patients from group 1 and 2 compared with the control group. ROC, receiver operator characteristic analysis; NLR, neutrophil/lymphocyte ratio; AUC, area under the curve; CI, confidence interval.

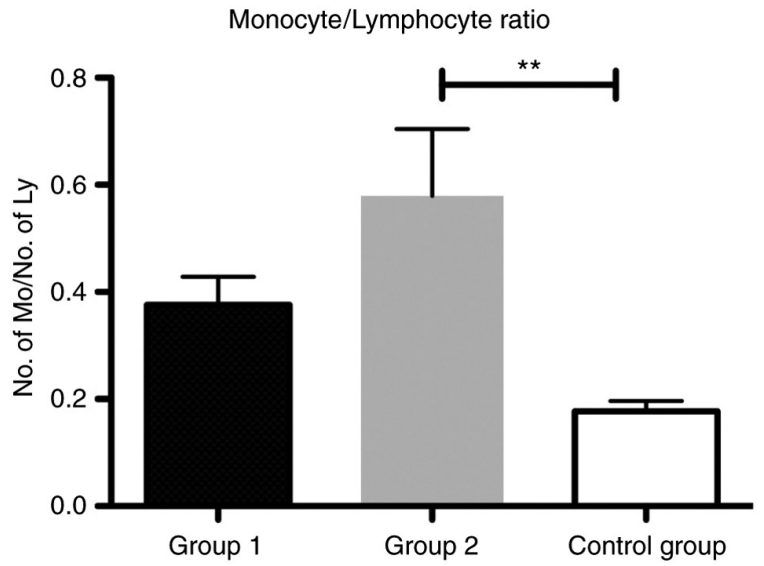

Figure 3. Bar plot (mean \pm SEM) of MLR in the liver cirrhosis patients from group 1 and 2 compared with the control group. One-way ANOVA test, ${ }^{* *} \mathrm{P}<0.01$. MLR, monocyte/lymphocyte ratio.

a significant increase in plasma oxidative stress markers, evaluated as thiobarbituric acid reactive substances (TBARS) and carbonylated protein (PCARB), confirming that oxidative stress acts as a continuous pathogenic mechanism in all stages of liver disease irrespective of the etiological factor. The increased synthesis of these products is due to an imbalance between different agents (ethanol, $\mathrm{HCV}$ or HBV) that trigger oxidative changes and the body's ability to scavenge reactive oxygen and nitrogen species (ROS and RNS) through its antioxidants, evaluated in the present study as total antioxidant capacity (TAC).

Involvement of oxidative stress in liver diseases has been extensively investigated and the impact of ROS and RNS in the pathogenesis of various liver diseases such as alcoholic liver disease (ALD), non-alcoholic fatty liver disease (NAFLD), viral hepatitis and hepatocellular cancer (HCC) has been reported $(5,9)$.

The liver is the main site of ethanol metabolism and also one of the first targets for alcohol-induced injuries. In alcoholic liver disease (ALD), metabolic processing of ethanol requires the activation of cytochrome P450 2E1 (CYP2E1) isoform that is able to commit formation of ROS. ROS can react with fatty acids from lipids to produce various peroxides which may undergo fragmentation to generate multiple reactive intermediates, mainly malondialdehyde (MDA) and 4-hydroxynonenal (4-HNE) (12). These are able to interact further with proteins and DNA forming adducts responsible for structural and functional alterations of liver cells and finally for cell death signaling. Alternative liver processing of ethanol through alcohol dehydrogenase reaction generates acetaldehyde, another reactive intermediate able to interact with proteins and DNA as well to form adducts that augment hepatocellular damage (29).

Through complex signaling pathways, alcohol consumption alters antioxidant systems involved in ROS removal. Finally, ROS may lead to excessive liver fibrosis and cirrhosis via activation of hepatic stellate cells that contribute to accumulation of the extracellular matrix within the liver (12).

It has been clearly established that $\mathrm{HCV}$ is associated with strong oxidative stress. HCV triggers oxidative stress by induction of several ROS-producing pathways: $\mathrm{Ca}^{2+}$-mediated mitochondrial dysfunction, NADPH oxidases (NOX), CYP2E1 and ER oxidoreductin-1 $\alpha$ (Ero1 $\alpha)$ (30). HCV core proteins are believed to possess the highest pro-oxidant potential to trigger mitochondrial dysfunction. However, another important factor responsible for $\mathrm{HCV}$-induced ROS production is the activation of several NOX isoforms (31).

Regarding chronic viral hepatitis B, many studies have shown that continuous HBV infection can promote the oxidative response, with patients exhibiting signs of pronounced oxidative stress in liver and blood $(32,33)$. Plasma of these patients is also characterized by elevated levels of ROS and oxidation products of lipids and proteins with a concomitant reduction in total antioxidant status (33).

Alteration of the pro-oxidant/antioxidant balance was revealed in liver and blood samples of patients using various techniques, either direct ROS/RNS quantification, identification of tissue storage of oxidative/nitrosative stress markers, measurement of lipid, protein and DNA oxidation products, or assessments of the individual antioxidants and total antioxidant capacity.

Quantification of MDA and 4-HNE (thiobarbituric acid reactive substances, TBARS) and of protein 

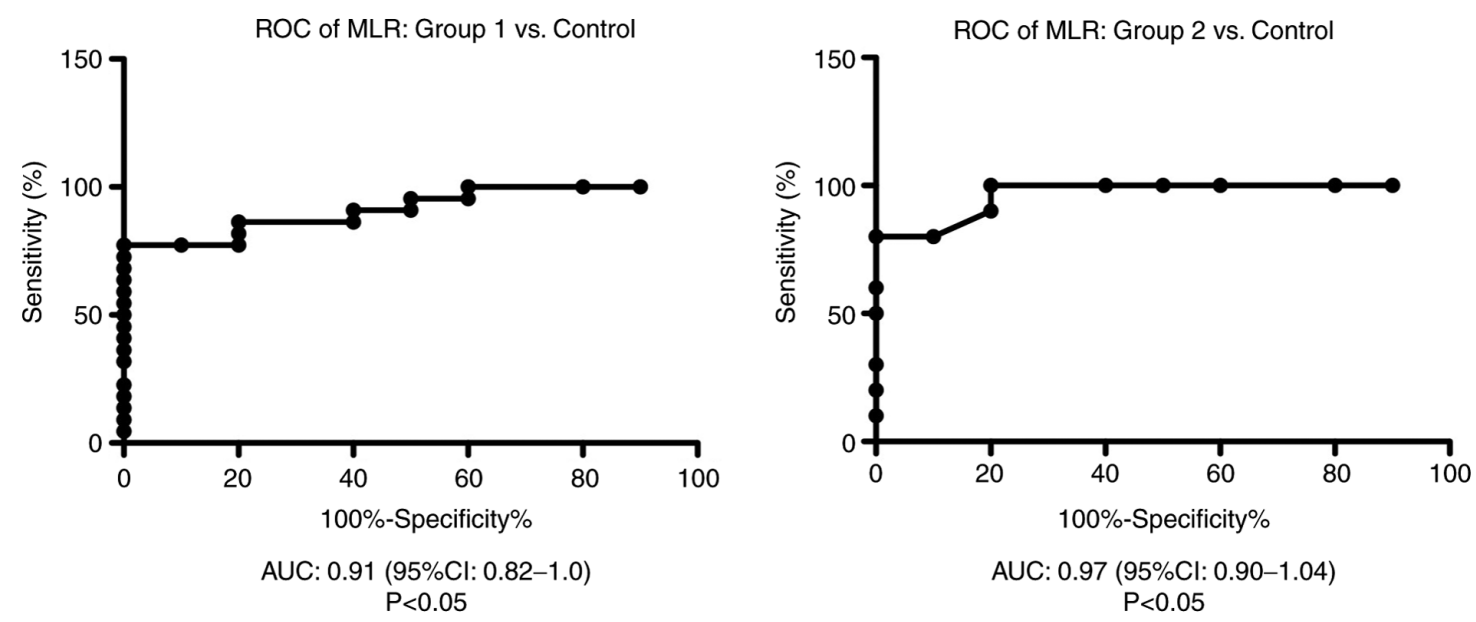

Figure 4. ROC diagram of MLR in the liver cirrhosis patients from group 1 and 2 compared with the control group. ROC, receiver operator characteristic analysis; MLR, monocyte/lymphocyte ratio; AUC, area under the curve; CI, confidence interval.

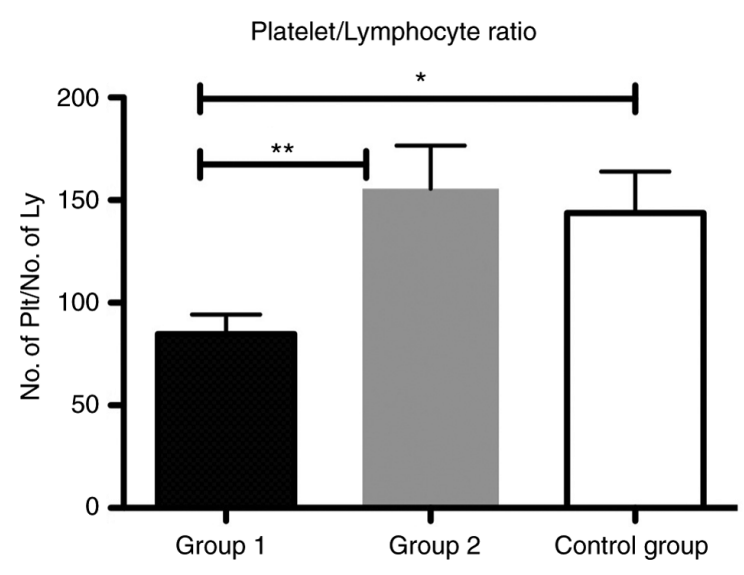

Figure 5. Bar plot (mean \pm SEM) of PLR in the liver cirrhosis patients from group 1 and 2 compared with the control group. One-way ANOVA test, ${ }^{*} \mathrm{P}<0.05,{ }^{* *} \mathrm{P}<0.01$. PLR, platelet/lymphocyte ratio.

carbonylation (PCARB) performed in our study as indexes of lipid peroxidation and protein oxidation respectively, are useful laboratory tools to explore redox status imbalance in liver diseases. Our results are congruent with those from other studies, with serum/plasma of the patients included in our study characterized by increased levels of lipid peroxides and protein carbonyl content.

As well as in ALD, another feature of oxidative stress in chronic hepatitis $\mathrm{B}$ and $\mathrm{C}$ is an impaired antioxidant capacity in liver and blood. These patients often exhibit reduced total blood glutathione levels and total antioxidant status, as well as an imbalance between oxidized and reduced glutathione in plasma and blood cells (12).

In our study, the values of the total antioxidant capacity did not differ significantly between the patients from the group with liver cirrhosis due to viral hepatitis and the control group. This finding could be explained by the fact that oxidative stress is biphasic: Low or moderate ROS concentrations trigger signaling cascades to switch on the antioxidant protection; instead, higher amounts of ROS inhibit the expression of gene coding antioxidant enzymes leading to cell damage. Moreover, the effects of viral proteins on antioxidants is different; some are induced (catalase, glutathione peroxidase) while others (SOD isoenzymes) are downregulated $(34,35)$. Thus, evaluation of a cumulative marker as TAC must be accompanied by an individual assessment of the most enzymatic and non-enzymatic antioxidants.

Individually, the roles of oxidative stress and inflammation in the pathophysiological events of gastrointestinal diseases, including liver disorders, have been extensively investigated for some time now $(36,37)$, yet, currently studies are exploring the interrelationship between oxidative stress and inflammation $(38,39)$. When the liver is attacked by exogenous or endogenous stimuli such as viruses and toxins, neutrophils, monocytes and lymphocytes infiltrate the liver and inflammation occurs to protect it from injury. Since many studies have shown that alterations in the amount of peripheral blood cells can demonstrate body inflammatory response, hematological indicators such as the neutrophil/lymphocyte (NLR), monocyte/lymphocyte (MLR) and platelet/lymphocyte (PLR) ratios have emerged as accepted biomarkers for the assessment of overall inflammatory status as well as significant prognostic factors for various inflammatory and ischemic conditions including cardiovascular diseases, different types of malignancies, and inflammatory bowel disease. NLR, PLR, and also MLR or LMR are simple and cost-effective biomarkers that can be easily derived from a cell blood counting diagram during routine examinations $(40,41)$.

As far as we know, there has been no investigation regarding the normal range of NLR, MLR and PLR in individuals from our country. In this study, we compared these hematological indicators in patients with toxic metabolic alcoholic cirrhosis and liver cirrhosis due to HCV and HBV infection and their association with oxidative stress markers in order to assess their usefulness to predict disease outcome in terms of the relationship between oxidative stress and inflammation. Our results are inconsistent with the intended purpose for some of the markers.

ROC analysis of the MLR showed that this index is a very good biomarker for increased inflammatory status estimation in both groups (toxic-metabolic liver cirrhosis and viral liver cirrhosis), with an AUC of 0.9136 (95\% CI: 0.82-1) in group 1 and 0.97 (95\% CI: 0.9-1.04) in group 2. Interestingly, we 

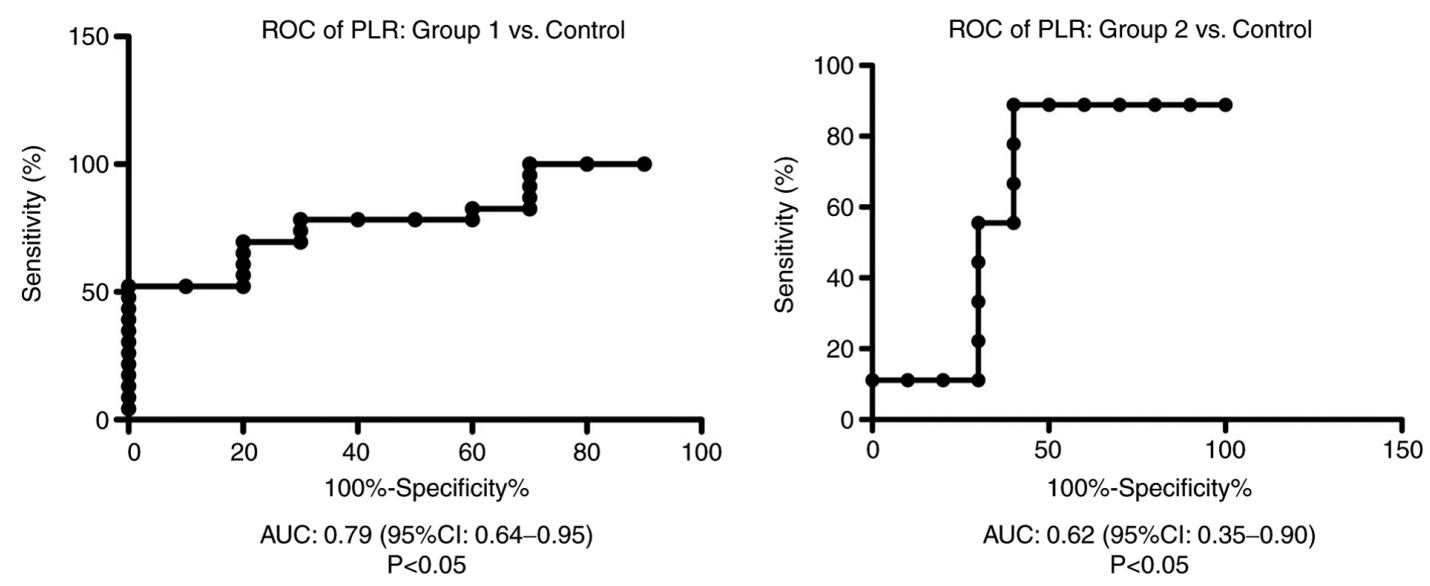

Figure 6. ROC diagram of in the liver cirrhosis patients from group 1 and 2 compared with the control group. ROC, receiver operator characteristic analysis; PLR, platelet/lymphocyte ratio; AUC, area under the curve; CI, confidence interval.

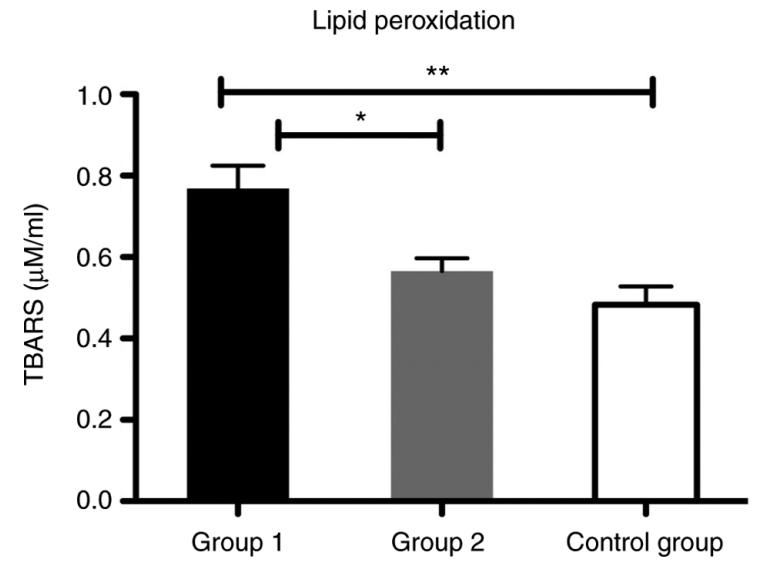

Figure 7. Bar plot (mean \pm SEM) of lipid peroxidation level in plasma in the healthy controls vs. liver cirrhosis group 1 and 2. One-way ANOVA with Tukey's multiple comparison test, ${ }^{*} \mathrm{P}<0.05,{ }^{* * *} \mathrm{P}<0.01$. TBARS, thiobarbituric acid reactive substances.

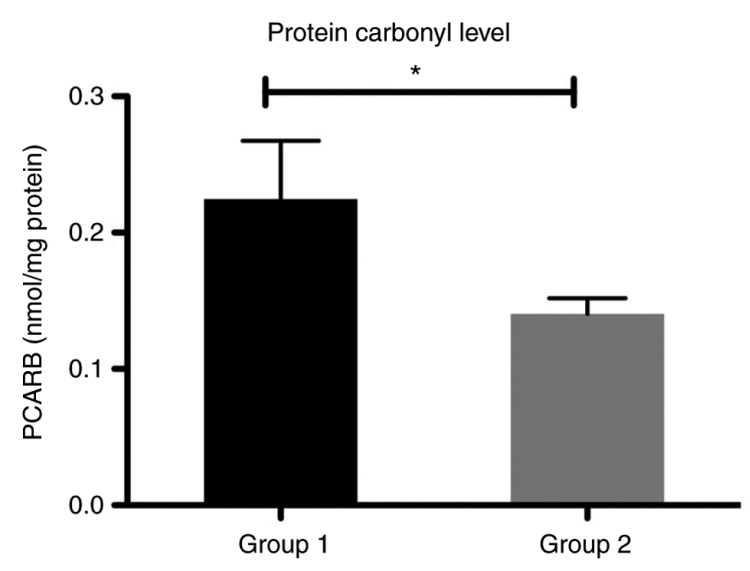

Figure 8. Bar plot (mean \pm SEM) of protein carbonyl levels in the plasma of patients with liver cirrhosis from groups 1 and 2. Mann-Whitney test, ${ }^{*} \mathrm{P}<0.05$. PCARB, protein carbonyl content.

founded that the NLR has a fair power for increased inflammatory status estimation in group 1 with an AUC of 0.79 (95\% CI: 0.64-0.94). In contrast, we found it to be a good tool for inflammatory status in group 2, with an AUC of 1.00

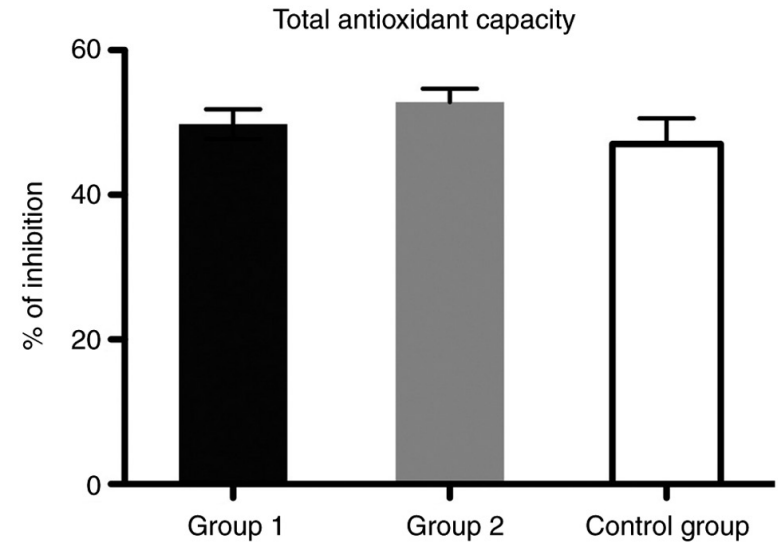

Figure 9. Bar plot (mean \pm SEM) of plasma total antioxidant capacity in healthy controls vs. liver cirrhosis group 1 and 2. One-way ANOVA with Bonferroni's multiple comparison test, $\mathrm{P}>0.05$; no significant differences were noted.

(95\% CI: 1.00-1.00). On the other hand, PLR was demonstrated to be a poor biomarker for both groups, with an AUC of 0.79 (95\% CI: 0.64-0.95) for group 1 and AUC of 0.62 (95\% CI: $0.35-0.9)$ in group 2.

These indicators have been previously described as predictive markers of disease progression, and they provide supplementary means for an effective management of chronic HBV, HCV infection and also ALD $(42,43)$. In addition, lymphocyte and platelet-related parameters have recently been investigated in alcohol consumption disorders (44). A retrospective analysis of patients with cirrhosis revealed that NLR is a biomarker of immune dysregulation in patients with cirrhosis; the associated risk of death persisting long after their initial hospitalization (45). Another study revealed that HBV-related-compensated cirrhosis patients had a significantly lower PLR, and HBV-related-decompensated cirrhosis patients had a significantly higher NLR than did any other patients (46).

Unfortunately, due to the limitation of our study, for none of these ratios between blood cells we did not find any significant correlation with oxidative stress markers (TBARS and PCARB) assessed as predictive markers for the unfavorable progression of liver cirrhosis. 
In conclusion, increased levels of oxidative stress markers and an insignificant alteration of total antioxidant capacity was found in our cirrhosis patients. In addition, we showed that NLR, MLR and PLR are easy-to-perform and accurate biomarkers associated with liver inflammatory status, even if they did not shown a significant correlation with all oxidative stress markers assessed.

Taken together, the data demonstrated that early detection of increased oxidative insult associated with a proinflammatory status can be a preclinical sign applied for proper intervention to support antioxidant homeostasis in order to limit an unfavorable disease progression.

However, a limitation of our study was the small number of patients included. Shortly after the beginning of our research, patient access to hospitals was restricted due to the pandemic period of SARS-Cov-2 infection. Thus, further exploration of these topics in a large cohort must be conducted.

\section{Acknowledgements}

This study is part of the PhD thesis of Mihnea Marian Pomacu from the University of Medicine and Pharmacy of Craiova, Romania. We are thankful to Mrs. Loredana Colhon from the Department of Biochemistry for the technical support.

\section{Funding}

This research received no external funding.

\section{Availability of data and materials}

The data analyzed during the current study are available from the authors on reasonable request.

\section{Authors' contributions}

Conceptualization of the study was achieved by MMP, VP, MDT, CGP and AMB. Methodology was designed by MMP, VP, AMA, ECS, DR and CGP. Formal analysis of the results were conducted by AMB, CGP and IMB. Data curation was conducted by MMP, VP, MDT, CGP and AMB. Writing of the manuscript was performed by MMP, CGP and AMB. Supervision was headed by AMB. All authors have read and agreed to the published version of the manuscript.

\section{Ethics approval and consent to participate}

The study was approved by The Ethics Committees of The University of Medicine and Pharmacy of Craiova, Romania (Nr. 116/11.11.2019). Patients included in this study provided informed consent for data publication.

\section{Patients consent for publication}

Not applicable.

\section{Competing interests}

The authors declare that they have no competing interests.

\section{References}

1. Ezhilarasan D: Oxidative stress is bane in chronic liver diseases: Clinical and experimental perspective. Arab J Gastroenterol 19: 56-64, 2018.

2. Romanelli RG and Stasi C: Recent advancements in diagnosis and therapy of liver cirrhosis. Curr Drug Targets 17: 1804-1817, 2016.

3. Asrani SK, Devarbhavi H, Eaton J and Kamath PS: Burden of liver diseases in the world. J Hepatol 70: 151-171, 2019.

4. D'Amico G, Garcio-Tsao G and Pagliaro L: Natural history and prognostic indicators of survival in cirrhosis: A systematic review of 118 studies. J Hepatol 44: 217-231, 2006.

5. Cederbaum AI, $\mathrm{Lu} \mathrm{Y}$ and $\mathrm{Wu} \mathrm{D}$ : Role of oxidative stress in alcohol-induced liver injury. Arch Toxicol 83: 519-548, 2009.

6. Zhou WC, Zhang QB and Qiao L: Pathogenesis of liver cirrhosis. World J Gastroenterol 20: 7312-7324, 2014.

7. Aruoma OI: Characterization of drugs as antioxidant prophylactics. Free Radic Biol Med 20: 675-705, 1996.

8. Valko M, Leibfritz D, Moncol J, Cronin MT, Mazur M and Telser J: Free radicals and antioxidants in normal physiological functions and human disease. Int J Biochem Cell Biol 39: 44-84, 2007.

9. Li S, Tan HY, Wang N, Zhang ZJ, Lao L, Wong CW and Feng Y: The role of oxidative stress and antioxidants in liver diseases. Int J Mol Sci 16: 26087-26124, 2015.

10. Poli G: Pathogenesis of liver fibrosis: Role of oxidative stress. Mol Aspects Med 21: 49-98, 2000.

11. Irshad M, Chaudhuri PS and Joshi YK: Superoxide dismutase and total anti-oxidant levels in various forms of liver diseases. Hepatol Res 23: 178-184, 2002.

12. Li S, Hong M, Tan HY, Wang N and Feng Y: Insights into the role and interdependence of oxidative stress and inflammation in liver diseases. Oxid Med Cell Longev 2016: 4234061, 2016.

13. Hao X, Li D, Wu D and Zhang N: The relationship between hematological indices and autoimmune rheumatic diseases (ARDs), a meta-analysis. Sci Rep 7: 10833, 2017.

14. Mititelu RR, Padureanu R, Băcănoiu M, Pădureanu V, Docea AO, Calina D, Barbulescu AL and Buga AM: Inflammatory and oxidative stress markers-mirror tools in rheumatoid arthritis. Biomedicines 8: 125, 2020.

15. Prabawa IPY, Bhargah A, Liwang F, Tandio DA, Tandio AL, Lestari AAW, Budiana ING and Manuaba IBAP: Pretreatment neutrophil-to-lymphocyte ratio (NLR) and platelet-to-lymphocyte ratio (PLR) as a predictive value of hematological markers in cervical cancer. Asian Pac J Cancer Prev 20: 863-868, 2019.

16. Fest J, Ruiter R, Ikram MA, Voortman T, van Eijck CHJ and Stricker BH: Reference values for white blood-cell-based inflammatory markers in the Rotterdam Study: A population-based prospective cohort study. Sci Rep 8: 10566, 2018.

17. Padureanu R, Albu CV, Mititelu RR, Bacanoiu MV, Docea AO, Calina D, Padureanu V, Olaru G, Sandu RE, Malin RD and Buga AM: Oxidative stress and inflammation interdependence in multiple sclerosis. J Clin Med 8: 1815, 2019.

18. Kartal O and Kartal AT: Value of neutrophil to lymphocyte and platelet to lymphocyte ratios in pneumonia. Bratisl Lek Listy 118: 513-516, 2017.

19. Angkananard T, Anothaisintawee T, McEvoy M, Attia J and Thakkinstian A: Neutrophil lymphocyte ratio and cardiovascular disease risk: A systematic review and meta-analysis. BioMed Res Int 2018: 2703518, 2018.

20. Liberski PS, Szewczyk M and Krzych LJ: Haemogram-derived indices for screening and prognostication in critically Ill septic shock patients: A case-control study. Diagnostics (Basel) 10: 638, 2020.

21. Gao K, Zhu W, Liu W, Ma D, Li H, Yu W, Wang L, Cao Y and Jiang Y: Diagnostic value of the blood monocyte-lymphocyte ratio in knee osteoarthritis. J Int Med Res 47: 4413-4421, 2019.

22. Liu J, Li S, Zhang S, Liu Y, Ma L, Zhu J, Xin Y, Wang Y, Yang C and Cheng Y: Systemic immune-inflammation index, neutrophil-to-lymphocyte ratio, platelet-to-lymphocyte ratio can predict clinical outcomes in patients with metastatic non-small-cell lung cancer treated with nivolumab. J Clin Lab Anal 33: e22964, 2019.

23. Liu J, Yeo HC, Doniger SJ and Ames BN: Assay of aldehydes from lipid peroxidation: Gas chromatography-mass spectrometry compared to thiobarbituric acid. Anal Biochem 245: 161-166, 1997.

24. Spanidis Y, Goutzourelas N, Stagos D, Mpesios A, Priftis A, Bar-Or D, Spandidos DA, Tsatsakis AM, Leon G and Kouretas D: Variations in oxidative stress markers in elite basketball players at the beginning and end of a season. Exp Ther Med 11: 147-153, 2016. 
25. Keles MS, Taysi S, Sen N, Aksoy H and Akçay F: Effect of corticosteroid therapy on serum and CSF malondialdehyde and antioxidant proteins in multiple sclerosis. Can J Neurol Sci 28: 141-143, 2001

26. Colombo G, Clerici M, Garavaglia ME, Giustarini D, Rossi R, Milzani A and Dalle-Donne I: A step-by-step protocol for assaying protein carbonylation in biological samples. J Chromatogr B Analyt Technol Biomed Life Sci 1019: 178-190, 2016.

27. Bradford MM: A rapid and sensitive method for the quantitation of microgram quantities of protein utilizing the principle of protein-dye binding. Anal Biochem 72: 248-254, 1976.

28. Janaszewska A and Bartosz G: Assay of total antioxidant capacity: Comparison of four methods as applied to human blood plasma. Scand J Clin Lab Invest 62: 231-236, 2002.

29. Zhu H, Jia Z, Misra H and Li YR: Oxidative stress and redox signaling mechanisms of alcoholic liver disease: Updated experimental and clinical evidence. J Dig Dis 13: 133-142, 2012.

30. Ivanov AV, Valuev-Elliston VT, Tyurina DA, Ivanova ON, Kochetkov SN, Bartosch B and Isaguliants MG: Oxidative stress, a trigger of hepatitis $\mathrm{C}$ and $\mathrm{B}$ virus-induced liver carcinogenesis. Oncotarget 8: 3895-3932, 2017.

31. Ivanov AV, Smirnova OA, Ivanova ON, Masalova OV, Kochetkov SN and Isaguliants MG: Hepatitis $\mathrm{C}$ virus proteins activate NRF2/ARE pathway by distinct ROS-dependent and independent mechanisms in HUH7 cells. PLoS One 6: e24957, 2011.

32. Alavian SM and Showraki A: Hepatitis B and its relationship with oxidative stress. Hepat Mon 16: e37973, 2016.

33. Xianyu J, Feng J, Yang Y, Tang J, Xie G and Fan L: Correlation of oxidative stress in patients with HBV-induced liver disease with HBV genotypes and drug resistance mutations. Clin Biochem 55: $21-27,2018$

34. Abdalla MY, Ahmad IM, Spitz DR, Schmidt WN and Britigan BE: Hepatitis C virus-core and non structural proteins lead to different effects on cellular antioxidant defenses. J Med Virol 76: 489-497, 2005.

35. Brault C, Lévy P, Duponchel S, Michelet M, Sallé A, Pécheur EI, Plissonnier ML, Parent R, Véricel E, Ivanov AV, et al: Glutathione peroxidase 4 is reversibly induced by HCV to control lipid peroxidation and to increase virion infectivity. Gut 65: 144-154, 2016.

36. Robles L, Vaziri ND and Ichii H: Role of oxidative stress in the pathogenesis of pancreatitis: Effect of antioxidant therapy. Pancreat Disord Ther 3: 112, 2013.

37. Tache DE, Stănciulescu CE, Baniţă IM, Purcaru ŞO, Andrei AM, Comănescu V and Pisoschi CG: Inducible nitric oxide synthase expression (iNOS) in chronic viral hepatitis and its correlation with liver fibrosis. Rom J Morphol Embryol 55 (Suppl 2): S539-S543, 2014.
38. Choghakhori R, Abbasnezhad A, Hasanvand A and Amani R: Inflammatory cytokines and oxidative stress biomarkers in irritable bowel syndrome: Association with digestive symptoms and quality of life. Cytokine 93: 34-43, 2017.

39. Popa SL, Leucuta DC and Dumitrascu DL: Pressure management as an occupational stress risk factor in irritable bowel syndrome: A cross-sectional study. Medicine (Baltimore) 97: e13562, 2018.

40. Avci BS, Avci A, Dönmez Y, Kaya A, Gülen M, Özer Aİ, Bulut A, Koç M, Nazik H and Satar S: The effectiveness of neutrophil-lymphocyte ratio in predicting In-hospital mortality in Non-ST-elevation myocardial infarction. Emerg Med Int 2020: 8718304,2020

41. Hu J, Zhou W, Zhou Z, Han J and Dong W: Elevated neutrophil-to-lymphocyte and platelet-to-lymphocyte ratios predict post-stroke depression with acute ischemic stroke. Exp Ther Med 19: 2497-2504, 2020.

42. Zhao Z, Liu J, Wang J, Xie T, Zhang Q, Feng S, Deng H and Zhong B: Platelet-to-lymphocyte ratio (PLR) and neutrophilto-lymphocyte ratio (NLR) are associated with chronic hepatitis $\mathrm{B}$ virus (HBV) infection. Int Immunopharmacol 51: 1-8, 2017.

43. Liu H, Zhang H, Wan G, Sang Y, Chang Y, Wang X and Zeng H: Neutrophil-lymphocyte ratio: A novel predictor for short-term prognosis in acute-on-chronic hepatitis B liver failure. J Viral Hepat 21: 499-507, 2014.

44. Orum MH and Kara MZ: Platelet to lymphocyte ratio (PLR) in alcohol use disorder. J Immunoassay Immunochem 41: 184-194, 2020.

45. Rice J, Dodge JL, Bambha KM, Bajaj JS, Reddy KR, Gralla J, Ganapathy D, Mitrani R, Reuter B, Palecki J, et al: Neutrophil-to-lymphocyte ratio associates independently with mortality in hospitalized patients with cirrhosis. Clin Gastroenterol Hepatol 16: 1786-1791.el, 2018.

46. Mao W and Wu J: Haematologic indices in hepatitis $\mathrm{B}$ virus-related liver disease. Clin Chim Acta 500: 135-142, 2020.

This work is licensed under a Creative Commons Attribution-NonCommercial-NoDerivatives 4.0 International (CC BY-NC-ND 4.0) License. 